\title{
Relative incompetence of European rabbits for Lyme disease spirochaetes
}

\author{
F.-R. MATUSCHKA ${ }^{1,2}$, T. W. SCHINKEL ${ }^{1}$, B. KLUG ${ }^{1}$, A. SPIELMAN ${ }^{2}$ and \\ D. R I CH'TE R ${ }^{1,2} *$ \\ ${ }^{1}$ Institut für Pathologie, Charité, Medizinische Fakultät der Humboldt-Universität zu Berlin, Malteserstraße 74-100, \\ 12249 Berlin, Germany \\ ${ }^{2}$ Department of Immunology and Infectious Diseases, Harvard School of Public Health, 665 Huntington Avenue, Boston, \\ $M A 02115, U S A$
}

(Received 4 December 1999; revised 1 March 2000; accepted 1 March 2000)

\section{SUMMARY}

To determine whether rabbits may serve as reservoir hosts for Lyme disease spirochaetes in Europe, we compared their competence as hosts for Borrelia afzelii, one of the most prevalent European spirochaetal variants, with that of the Mongolian jird. To infect rabbits or jirds, at least 3 nymphal or adult Ixodes ricinus ticks infected with spirochaetes fed to repletion on each animal. Whereas jirds readily acquired tick-borne Lyme disease spirochaetes and subsequently infected vector ticks, rabbits exposed to tick-borne spirochaetes rarely became infectious to ticks. Only the rabbit that was infectious to ticks developed an antibody response. To the extent that I. ricinus ticks feed on European rabbits, these mammals may be zooprophylactic by diverting vector ticks from more suitable reservoir competent hosts.

Key words: Lyme disease, Borrelia afzelii, rabbits, jirds.

\section{INTRODUCTION}

The agent of Lyme disease, Borrelia burgdorferi s.1., parasitizes various mammals that might serve as reservoir hosts. Palearctic Apodemus spp. and nearctic Peromyscus spp. mice appear to serve as the main reservoir hosts of these pathogens in nature (Matuschka et al. 1992; Spielman, 1994). Although particular birds are reservoir-competent for Lyme disease spirochaetes, their role in the epizootiology of this pathogen remains uncertain (Richter et al. 2000). Rabbits, Oryctolagus cuniculus, too, are abundant in the European ecotonal habitat that is most frequently infested by the Ixodes ricinus ticks that serve as vectors for these spirochaetes. Rabbits may be densely parasitized by all 3 stages of this vector tick (Milne, 1949; Gilot, Rogers \& Lachet, 1985; Matuschka et al. 1994). The brush rabbit, Sylvilagus bachmani, of California may be infected in nature (Lane \& Regnery, 1989) and North American cottontail rabbits, Sylvilagus floridanus, serve as a reservoir for a related spirochete, $B$. andersonii, in a cycle that includes rabbits and a rabbit-specific tick, Ixodes dentatus (Anderson et al. 1989; Telford \& Spielman, $1989 a, b$; Marconi, Liveris \& Schwartz, 1995). Other lagomorphs, such as varying and European hares, may harbour Lyme disease spiro-

* Corresponding author: Institut für Pathologie, Charité, Medizinische Fakultät der Humboldt-Universität zu Berlin, Malteserstraße 74-100, 12249 Berlin, Germany. Tel: +4930 8387 0374. Fax: +4930776 2085. E-mail: drichter@charite.de chaetes and infect vector ticks (Jaenson \& Tälleklint, 1996). In laboratory experiments, New Zealand white rabbits appeared to be spirochaete-competent (Burgdorfer et al. 1983; Foley et al. 1997). In the event that rabbits serve such a reservoir role in Central Europe, they would readily become infected in nature, would permit spirochaete multiplication and ultimately become infectious for another cohort of vector ticks. Because the spirochaete-competence of European rabbits remains unknown, we determined whether these potentially important reservoir hosts are readily infected by $B$. afzelii, one of the most prevalent variants of Lyme disease spirochaetes infecting vector ticks and small rodents in Europe (Richter et al. 1999).

\section{MATERIALS AND METHODS}

Mongolian jirds, Meriones unguiculatus, and European rabbits, Oryctolagus cuniculus, were used as hosts for ticks in these experiments. Rabbits were 2 months old when first exposed to the bites of ticks and jirds were 3-4 months of age. On rabbits, nymphs or similar numbers of adult male and female ticks were placed in cotton bags that enclosed the ears. Jirds were bred in our laboratory from animals that had originally been purchased from Charles River Laboratories (Sulzfeld, Germany). Jirds were enclosed in wire-mesh cylinders, and subadult ticks were brushed onto their bodies (Matuschka et al. 1997, 1998). After the ticks attached, each jird was transferred to a wire-mesh cage suspended over a 
pan of water. The jirds remained in these cages until all ticks became replete and had detached. Detached ticks were removed twice daily.

Non-infected $I$. ricinus ticks used in these experiments had originally been collected in Berlin, Germany and were in their third generation of laboratory rearing. Ticks were maintained in screened vials and stored at $18-22{ }^{\circ} \mathrm{C}$ in sealed desiccator jars containing supersaturated $\mathrm{MgSO}_{4}$ with a photo-period of $16: 8$ (L:D) h. Nymphs were permitted to feed to repletion on jirds and adults on rabbits.

The isolate of B. burgdorferi s.l. used in these experiments originated from a naturally infected nymphal $I$. ricinus tick collected from vegetation in suburban Berlin, Germany, and was maintained by serial passage between ticks and jirds. The genospecies was identified as B. afzelii (Matuschka et al. 1998). Larval ticks were permitted to engorge on a jird 2 weeks after it had been infected via tick-bite. Such replete ticks were held at $22^{\circ} \mathrm{C}$, and 10 were dissected about 1 month after moulting to the nymphal stage. Their midgut content were examined, and all proved to contain spirochaetes. This cohort of ticks was used for all rabbits, except for 1 that was infected by means of field-collected adult $I$. ricinus ticks derived from an urban part in Göttingen, Germany.

A xenodiagnostic procedure was used to determine whether vertebrate hosts exposed to infected ticks had become infectious for vector ticks. Thus, nonfed, non-infected larvae or nymphs were permitted to engorge on an animal and to feed to repletion, at 2 and again at 4 weeks after exposure to infected ticks. Xenodiagnostic ticks had access to sites where infecting ticks had fed 2 and 4 weeks previously. These ticks were permitted to develop to the next developmental stage and were dissected about 6-8 weeks later, after they had defaecated. Spirochaetal infection was determined in nymphs, either by polymerase chain reaction (PCR) using the entire body of the tick or by dark-field microscopy of its gut contents. The midgut of each adult tick was hemisected and 1 segment subjected to each of the 2 diagnostic procedures.

To detect spirochaetes in vector ticks, midgut contents were smeared onto a glass slide in $4 \mu \mathrm{l}$ of physiological saline, covered with a cover-slip and examined by means of dark-field microscopy (Laborlux equipped with $\times 25$ and $\times 40$ Fluotar objectives; Leitz, Wetzlar, Germany). To detect spirochaetal DNA in ticks, homogenates were analysed by a nested PCR amplifying a fragment of the gene encoding the outer surface protein A (OspA) (Eiffert et al. 1995). Ticks were prepared individually by dissecting their opisthosomas with a 27-gauge needle. Midgut suspensions were incubated with $20 \mu \mathrm{l}$ of proteinase $\mathrm{K}(20 \mathrm{mg} / \mathrm{ml})$ in ATL-buffer (Qiagen, Hilden, Germany) for 3-4 h or overnight at $55^{\circ} \mathrm{C}$. DNA was extracted using the QIAamp Tissue Kit (Qiagen) and stored at $-20^{\circ} \mathrm{C}$ until used. The following sequences were used as primers: outer primer pair $\left(5^{\prime}-3^{\prime}\right)$ GGTC'TAATATTAGCCTTAATAGCATG and TCAGCAGCTAGAGTTCCTTCAAG; inner primer pair CATGTAAGCAAAATGTTAGCAGCC and CTGTGTATTCAAGTCTGGTTCC. Samples $(10 \mu \mathrm{l})$ of the suspension were diluted to $50 \mu \mathrm{l}$ using $200 \mathrm{~m}$ each of dN'TP, $4 \mathrm{mM}_{\mathrm{MgCl}_{2}}, 5 \mu \mathrm{l} 10 \times \mathrm{PCR}$ buffer, $0.5 \mathrm{U}$ of $\mathrm{Taq}$ polymerase (Perkin-Elmer, Branchburg, NJ) as well as $10 \mathrm{pmol}$ of the outer primer pair and $20 \mathrm{pmol}$ of the inner primer pair, respectively. The vial containing the mixture was placed in a thermocycler (PTC 200, MJ Research, Watertown, MA), heated for $3 \mathrm{~min}$ at $96^{\circ} \mathrm{C}$ and subjected to 40 cycles of $30 \mathrm{~s}$ denaturation at $96^{\circ} \mathrm{C}, 30 \mathrm{~s}$ each for the first annealing reaction at $59{ }^{\circ} \mathrm{C}$, and for the second at $58^{\circ} \mathrm{C}$ and with a $30 \mathrm{~s}$ extension at $72{ }^{\circ} \mathrm{C}$. The last extension at $72{ }^{\circ} \mathrm{C}$ lasted $2 \mathrm{~min}$. Subsequently, $5 \mu \mathrm{l}$ of the product was transferred to a fresh tube containing $45 \mu \mathrm{l}$ of reaction mixture as described and the inner set of primers. PCR products of the second amplification were detected by electrophoresis in a $3 \%$ agarose gel and stained with ethidium bromide. To provide a positive control, a sample of $100 \mathrm{fg}$ of B. burgdorferi s.1. DNA was included in each series of amplification.

The presence of antibodies against Lyme disease spirochaetes in sera of animals exposed to infected ticks was determined by enzyme-linked immunosorbent assays (ELISA). Sera were obtained from rabbits or jirds before and 6 weeks after exposure to infected ticks. For the ELISA, a commercial kit based on the flagellum antigen was employed (Dako A/S, Glostrup, Denmark). Sera were diluted 1:200 in phosphate-buffered saline with $0.1 \%$ Tween 20 (PBS-Tween) and $100 \mu \mathrm{l}$ of solution were added per well in duplicate. Following a 2 -h incubation at room temperature, the plate was washed 4 times with PBS-Tween using an automatic ELISA-washer (Wellwash, Dentley, UK). Alkaline phosphataseconjugated anti-rabbit or anti-mouse antibodies were diluted 1:1000 and $100 \mu \mathrm{l}$ were added in the respective wells. After a $1-\mathrm{h}$ incubation at room temperature and 4 washes, $200 \mu \mathrm{l}$ of substrate pNPP were added to each well and incubated for $30 \mathrm{~min}$ in darkness. Optical density of each well was determined at $405 \mathrm{~nm}$ with a Spectramax Plus ELISA reader (Molecular Devices, Sunnyvale, USA).

\section{RESULTS}

We determined whether tick-borne Lyme disease spirochaetes are transmissible to European rabbits as readily as to jirds. At least 3 nymphal ticks from a cohort experimentally infected with $B$. afzelii were permitted to engorge on each of 5 jirds and at least 5 nymphs or 9 adult ticks to feed on each of 6 rabbits; additionally, 1 rabbit was exposed to 11 field-derived 
Table 1. Susceptibility to Lyme disease spirochaetes and infectivity to vector ticks of rabbits and jirds

(Spirochaete infection diagnosed by dark-field microscopy (DF) or polymerase chain reaction (PCR) in nymphal and adult Ixodes ricinus ticks that engorged as larvae and nymphs, respectively, on rabbits or jirds after they were exposed to spirochaete-infected ticks. * Field-derived ticks.)

\begin{tabular}{|c|c|c|c|c|c|c|c|c|}
\hline \multirow[b]{4}{*}{ Host } & \multirow{3}{*}{\multicolumn{3}{|c|}{ Infecting ticks }} & \multicolumn{5}{|c|}{ Xenodiagnostic ticks } \\
\hline & & & & \multicolumn{4}{|c|}{ No. examined } & \multirow[b]{3}{*}{$\begin{array}{l}\text { No. } \\
\text { infected }\end{array}$} \\
\hline & & & & \multicolumn{2}{|c|}{ Nymphs } & \multicolumn{2}{|c|}{ Adults } & \\
\hline & Stage & No. & $\begin{array}{l}\% \text { cohort } \\
\text { infected }\end{array}$ & DF & PCR & $\overline{\mathrm{DF}}$ & PCR & \\
\hline \multicolumn{9}{|l|}{ Jird } \\
\hline 1 & $\mathrm{Ny}$ & 4 & 100 & 5 & 0 & 0 & 0 & 5 \\
\hline 2 & $\mathrm{Ny}$ & 4 & 100 & 5 & 0 & 0 & 0 & 4 \\
\hline 3 & $\mathrm{Ny}$ & 3 & 100 & 5 & 0 & 0 & 0 & 5 \\
\hline 4 & $\mathrm{Ny}$ & 3 & 100 & 5 & 0 & 0 & 0 & 4 \\
\hline 5 & $\mathrm{Ny}$ & 14 & 100 & 11 & 0 & 0 & 0 & 11 \\
\hline \multicolumn{9}{|c|}{ Rabbit } \\
\hline 1 & $\mathrm{Ny}$ & 5 & 100 & 21 & 0 & 16 & 4 & 0 \\
\hline 2 & $\mathrm{Ny}$ & 7 & 100 & 22 & 10 & 14 & 13 & 0 \\
\hline 3 & $\mathrm{Ny}$ & 13 & 100 & 20 & 20 & 15 & 15 & 0 \\
\hline 4 & $\mathrm{Ny}$ & 14 & 100 & 40 & 20 & 20 & 20 & 4 \\
\hline 5 & $\mathrm{Ad}$ & 14 & 80 & 20 & 40 & 20 & 20 & 0 \\
\hline 6 & $\mathrm{Ad}$ & 9 & 80 & 21 & 20 & 11 & 11 & 0 \\
\hline 7 & $\mathrm{Ad}$ & $11 *$ & 33 & 3 & 0 & 13 & 11 & 0 \\
\hline
\end{tabular}

Table 2. Spirochaete infection diagnosed by dark-field microscopy (DF) or polymerase chain reaction (PCR) in nymphal and adult Ixodes ricinus ticks that engorged as larvae and nymphs, respectively, on rabbits or jirds 2 and 4 weeks after these hosts had been exposed to spirochaete-infected ticks

\begin{tabular}{|c|c|c|c|c|c|c|c|c|}
\hline \multirow[b]{4}{*}{ Host } & \multicolumn{8}{|c|}{ Xenodiagnostic ticks examined } \\
\hline & \multirow[b]{3}{*}{ Stage } & \multicolumn{4}{|c|}{2 weeks p.i. by } & \multicolumn{3}{|c|}{4 weeks p.i. by } \\
\hline & & \multicolumn{2}{|l|}{ DF } & \multicolumn{2}{|c|}{ PCR } & \multicolumn{2}{|l|}{$\mathrm{DF}$} & PCR \\
\hline & & No. & $\%$ inf. & No. & $\%$ inf. & No. & $\%$ inf. & No. $\%$ inf. \\
\hline \multicolumn{9}{|l|}{ Jird } \\
\hline 5 & Nymph & 5 & 100 & 0 & - & 6 & 100 & $0-$ \\
\hline \multicolumn{9}{|l|}{ Rabbit } \\
\hline 4 & Nymph & 20 & 0 & 10 & 0 & 20 & 10 & 100 \\
\hline 4 & Adult & 10 & 0 & 10 & 20 & 10 & 0 & 100 \\
\hline
\end{tabular}

ticks that may have contained various genospecies of Lyme disease spirochaetes (Table 1). To determine whether these animals had acquired infection and had subsequently become infectious to ticks, noninfected xenodiagnostic ticks were permitted to feed on each animal. At 2 and at 4 weeks after exposure to infected ticks, rabbits were infested with xenodiagnostic larval and nymphal ticks and jirds with larval ticks. After the replete ticks had moulted to their subsequent stage, their midgut contents were analysed for the presence of spirochaetes by dark- field microscopy and by PCR. Spirochaetes were detected microscopically in virtually all of the nymphs that had engorged as larvae on these jirds, 2 and 4 weeks after exposure to tick-borne infection (Table 2). None of the xenodiagnostic ticks feeding on the 3 rabbits exposed to infected adult ticks contained spirochaetes. Of the 4 rabbits that had been exposed to infected nymphal ticks, only 1 was infectious to xenodiagnostic ticks. One fifth of the examined ticks that had fed as nymphs on this rabbit 2 weeks after the tick-borne infection contained 


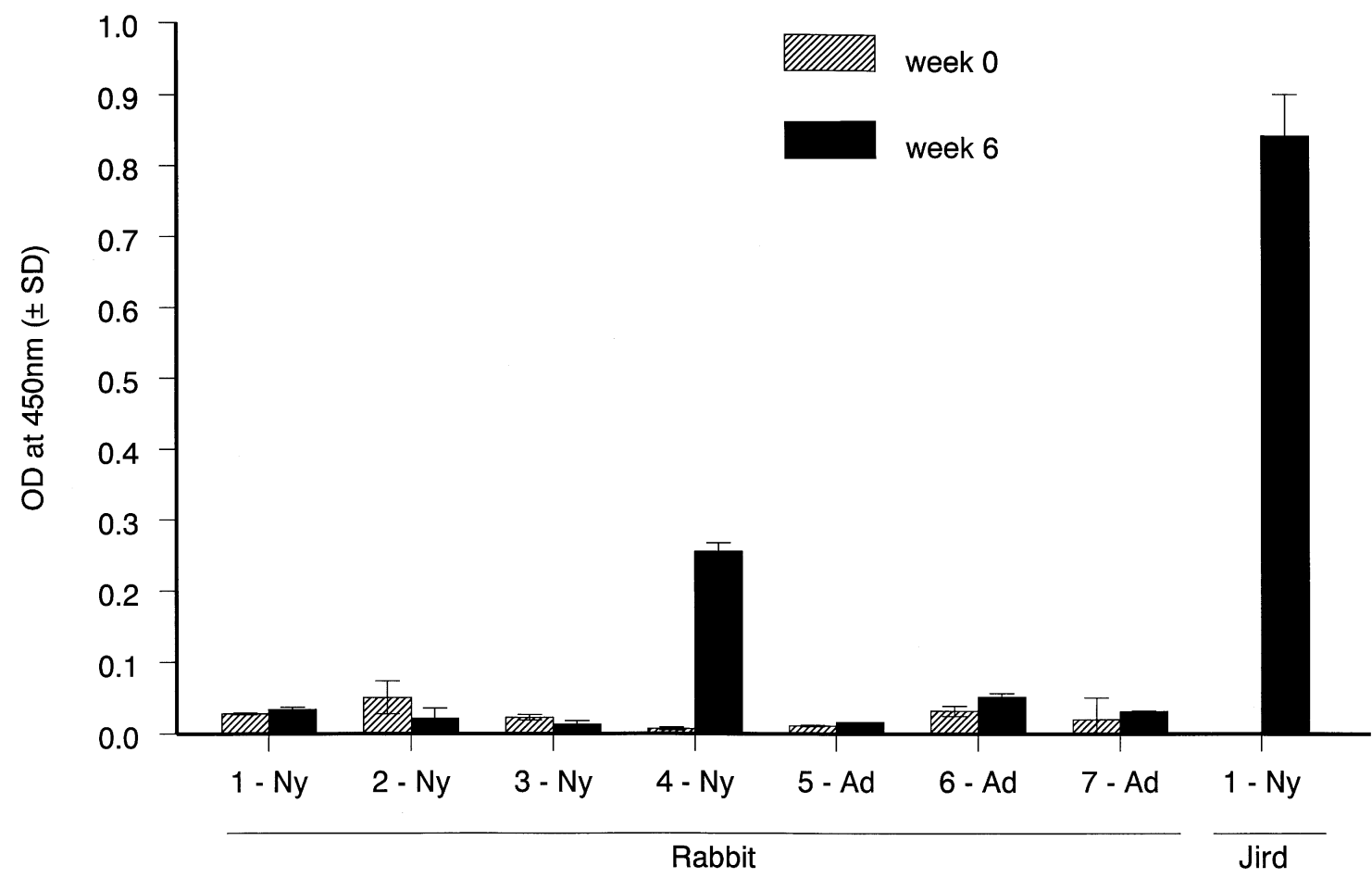

Fig. 1. Levels of antibodies specific for Lyme disease spirochaetes in rabbits and jirds before and 6 weeks after they were exposed to spirochaete-infected nymphal ( $\mathrm{Ny}$ ) or adult (Ad) ticks. Antibodies were detected by means of an enzyme-linked immunosorbent assay.

spirochaetal DNA. In addition, spirochaetes were detected microscopically in 2 out of 20 ticks that had fed as larvae 4 weeks after exposure to infected ticks. Whereas jirds readily acquire tick-borne Lyme disease spirochaetes and subsequently infect vector ticks, rabbits exposed to tick-borne spirochaetes rarely become infectious to ticks.

To confirm that spirochaetes actually were present in the presumably infected ticks that were used to infect these experimental animals, we analysed by dark-field microscopy the gut contents of nymphal and adult ticks in each infecting cohort. Virtually all such laboratory-reared ticks and a third of the fieldderived ticks proved to be infected (Table 1). At least 3 spirochaete-infected ticks fed to repletion on each of our experimental jirds or rabbits.

To detect seroconversion in the rabbits and jirds that had been exposed to infected ticks, we analysed their sera for the presence of antibodies specific for Lyme disease spirochaetes. Sera obtained from the animals before exposure and 6 weeks later were analysed by ELISA. All jirds that were infected by tick-bite generated anti-spirochaetal antibodies (representative shown in Fig. 1). Of the rabbits that were exposed to tick-borne spirochaetes, only the rabbit that was infectious to vector ticks developed an antibody response.

\section{ISCUSSION}

Lagomorph hosts may contribute naturally to the perpetuation of Lyme disease spirochaetes. In Europe, some I. ricinus vector ticks acquire spiro- chaetal infection in the course of feeding on varying hares, Lepus timidus, or on European hares, L. europaeus, in island sites where biodiversity is restricted (Tälleklint \& Jaenson, 1993; Jaenson \& Tälleklint, 1996). Lyme disease-like spirochaetes infect cottontail rabbits in northeastern North America in an independent enzootic cycle involving the rabbit-specific tick, I. dentatus. The sera of virtually all such rabbits react against antigens of Lyme disease spirochaetes (Telford \& Spielman, $1989 b$ ). These spirochaetes are morphologically, antigenically and genetically distinct from $B$. burgdorferi s.1. (Anderson et al. 1989) and have been reclassified as a distinct species, now designated as $B$. andersonii (Marconi et al. 1995). Although the deer ticks, Ixodes dammini, that transmit the agent of human Lyme disease occasionally infest these lagomorphs, no human infections due to $B$. andersonii have yet been noted, and spirochaete variants pathogenic for people have not yet been discovered in such rabbits. Along the Pacific coast of North America, brush rabbits and black-tailed jackrabbits, Lepus californicus, are similarly seroreactive (Lane \& Regnery, 1989). In Europe, particular lagomorphs appear to perpetuate the cycle of transmission of Lyme disease spirochaetes in nature, but mainly where biodiversity is restricted.

The competence of rabbits as hosts for European Lyme disease spirochaetes may differ from that of spirochaetes native of North America. A competent reservoir for a vector-borne pathogen must be susceptible to the pathogen delivered via the bite of 
the vector, must support its proliferation and must subsequently become infectious to the vector. Indeed, laboratory rabbits can be infected via the bites of deer ticks infected by B. burgdorferi s.s. (Benach $e t$ al. 1987), and spirochaetes were cultured from the skin of all rabbits that had been parasitized by such ticks (Piesman et al. 1991). Seroconversion, however, has been recorded only in a quarter of such tickinfected rabbits (Kornblatt, Steere \& Brownstein, 1984), which corresponds to our finding in the case of rabbits exposed to $B$. afzelii-infected $I$. ricinus ticks. Infection is transmitted to diverse Ixodes ticks in the course of feeding on laboratory rabbits, but only transiently (Burgdorfer, 1984; Telford \& Spielman, 1989a). Tick-transmitted B. afzelii spirochaetes only infrequently produce infections in rabbits the subsequently infect $I$. ricinus ticks. Rabbits appear to be even less competent as hosts for European B. afzelii than for North American $B$. burgdorferi s.s. spirochaetes.

B. afzelii spirochaetes appear not to perpetuate effectively in lagomorphs, and this may have particular relevance for the epizootiology of Lyme disease in Europe because this spirochaetal variant is frequent there. European rabbits may be extraordinarily abundant in the ecotonal sites in which the agent of Lyme disease is transmitted in Central Europe (Thompson \& King, 1994), and dozens may occur on a hectare of land. To the extent that $I$. ricinus ticks feed on European rabbits (Milne, 1949), these mammals would be zooprophylactic for the agent of Lyme disease by diverting vector ticks from more reservoir competent hosts.

We thank Professor Dr Eberhard Schein for support regarding the animals and Susanne Marburg for excellent technical assistance. This study was supported by grant Ma 942/10-1 from the Deutsche Forschungsgemeinschaft. Animal experimentation adhered to German legislative requirements under the terms of a permit issued for this purpose.

\section{REFERENCES}

ANDERSON, J. F., MAGNARELli, L. A., LEFEBVRE, R. B., ANDREADis, T. G., McANinCH, J. B. P. G. \& JOHNSON, R. C. (1989). Antigenically variable Borrelia burgdorferi isolated from cottontail rabbits and Ixodes dentatus in rural and urban areas. Fournal of Clinical Microbiology 27, 13-20.

BENACH, J. L., COlEMAN, J. L., SKinNeR, R. A. \& BOSLER, E. M. (1987). Adult Ixodes dammini on rabbits: a hypothesis for the development and transmission of Borrelia burgdorferi. Fournal of Infectious Diseases $\mathbf{1 5 5}$, 1300-1306.

BURgdorfer, w. (1984). The New Zealand white rabbit: an experimental host for infecting ticks with Lyme disease spirochetes. Yale Fournal of Biology and Medicine 57, 609-612.

BURgdorfer, W., BARbour, A. G., HAYes, S. F., PÉTER, O. \&
AESCHLIMANN, A. (1983). Erythema chronicum migrans - a tickborne spirochetosis. Acta Tropica 40, 79-83.

EIfFERT, H., OHLENBUSCH, A., CHRISTEN, H.-J., THOMSSEN, R., SPIElman, A. \& MATUSChKA, F.-R. (1995).

Nondifferentiation between Lyme disease spirochetes from vector ticks and human cerebrospinal fluid. Fournal of Infectious Diseases 171, 476-479.

FOLEY, D. M., WANG, Y.-P., WU, X.-Y., BLANCO, D. R., LOVETT, M. A. \& MILleR, J. N. (1997). Acquired resistance to Borrelia burgdorferi infection in the rabbit. Comparison between outer surface protein $\mathrm{A}$ vaccine- and infection-derived immunity. Fournal of Clinical Investigation 99, 2030-2035.

Gilot, B., Rogers, P. \& LACHet, B. (1985). Données biologiques et écologiques sur les tiques de lagomorphes (et plus spécialement celles du lapin de garenne, Oryctolagus cuniculus L.) dans les Alpes françaises et leur avant-pays. Acarologia 26, 335-354.

JAENSON, T. G. T. \& TÄLlEKLINT, L. (1996). Lyme borreliosis spirochetes in Ixodes ricinus (Acari: Ixodidae) and the varying hare on isolated islands in the Baltic Sea. Fournal of Medical Entomology 33, 339-343.

KORnblatt, A. N., STEERE, A. C. \& BROWNSTEIN, D. G. (1984). Infection in rabbits with the Lyme disease spirochete. Yale Fournal of Biology and Medicine 57, 613-614.

LANE, R. S. \& REGNERY, D. C. (1989). Lagomorphs as sentinels for surveillance of borreliosis in the far western United States. Fournal of Wildlife Diseases 25, 189-193.

MARCONI, R. T., LIVERIS, D. \& SCHWARTZ, I. (1995). Identification of novel insertion elements, restriction fragment length polymorphism patterns, and discontinuous 23S rRNA in Lyme disease spirochetes: phylogenetic analyses of rRNA genes and their intergenic spacers in Borrelia japonica sp. nov. and genomic group 21038 (Borrelia andersonii sp. nov.) isolates. Fournal of Clinical Microbiology 33, 2427-2434.

MATUSCHKA, F.-R., EIFFERT, H., OHLENBUSCH, A., RICHTER, D., Schein, E. \& SPIElman, A. (1994). Transmission of the agent of Lyme disease on a subtropical island. Tropical Medicine and Parasitology 45, 39-44.

MATUSCHKA, F.-R., ENDEPOls, S., RichteR, D. \& SPIELMAN, A. (1997). Competence of urban rats as reservoir hosts for Lyme disease spirochetes. Fournal of Medical Entomology 34, 489-493.

MATUSCHKA, F.-R., FISCHER, P., HEILER, M., RICHTER, D. \& SPIELMAN, A. (1992). Capacity of European animals as reservoir hosts for the Lyme disease spirochete. Fournal of Infectious Diseases 165, 479-483.

MATUSChKa, F.-R., SCHINKEL, T. W., KLUG, B., SPIELMAN, A. \& RICHTER, D. (1998). Failure of Ixodes ticks to inherit Borrelia afzelii infection. Applied and Environmental Microbiology 64, 3089-3091.

MiLne, A. (1949). The ecology of the sheep tick, Ixodes ricinus L. Host relationships of the tick. Part 2. Observations on hill and moorland grazings in northern England. Parasitology 39, 173-197.

Piesman, J., MaUpin, G. O., CAMPos, E. G. \& HaPP, C. M. (1991). Duration of adult female Ixodes dammini 
attachment and transmission of Borrelia burgdorferi, with description of a needle apiration isolation method. Fournal of Infectious Diseases 163, 895-897.

RiCHTER, D., ENDEPOls, S., OHLENBUSCH, A., EIFFERT, H., SPielman, A. \& Matuschka, F.-R. (1999). Genospecies diversity of Lyme disease spirochetes in rodent reservoirs. Emerging Infectious Diseases 5, 291-296.

RiCHTER, D., SPIELMAN, A., KOMAR, N. \& MATUSCHKA, F.-R. (2000). Competence of American robins as reservoir hosts for Lyme disease spirochetes. Emerging Infectious Diseases 6, 133-138.

SPIElman, A. (1994). The emergence of Lyme disease and human babesiosis in a changing environment. Annals of the New York Academy of Sciences 740, 146-156.
TÄLlEKLINT, L. \& JAENSON, T. G. T. (1993). Maintenance by hares of European Borrelia burgdorferi in ecosystems without rodents. Fournal of Medical Entomology 30, 273-276.

TElford, S. R. \& SPIElman, A. (1989a). Competence of a rabbit-feeding Ixodes dentatus (Acari: Ixodidae) as a vector of the Lyme disease spirochete. Fournal of Medical Entomology 26, 118-121.

TElFord, s. R. \& SPIELMAN, A. (1989b). Enzootic transmission of the agent of Lyme disease in rabbits. American Fournal of Tropical Medicine and Hygiene 41, 482-490.

Thompson, H. v. \& KIng, c. M. (1994). The European Rabbit. The History and Biology of a Successful Colonizer. Oxford University Press, Oxford. 